\title{
Review on Post-Harvest and Green Bean Coffee Processing in Ethiopia
}

\section{Bikila Ollika Fufa*, Muluneh Bekele Etana and Mosissa Chewaka Aga}

Department of Horticulture, College of Agriculture and Veterinary Science, Ambo University, Ambo, Ethiopia

*Corresponding Author: Bikila Ollika Fufa, Department of Horticulture, College of Agriculture and Veterinary Science, Ambo University, Ambo, Ethiopia.

Received: April 13, 2019; Published: June 20, 2019

\begin{abstract}
Coffee (Coffea Arabica L.) is the major source of currency for Ethiopia and contributes more than 35\% of the total export earnings. It is originated in Ethiopia. Coffee belongs to the family Rubiacea and the genus Coffea. The two main species of Coffee cultivated on a world scale are Arabica Coffee (Coffea arabica L.) and Robusta Coffee (Coffea canaphora L.), which account for about 98-99\% of the world Coffee production. Even if the high production potential and economic importance of Coffee production and productivity of crop is still limited due to post-harvest handling and processing problems. Coffee processing is aimed to lower the water content of fresh cherries to a level which allows the preservation of beans (about 11-12\%), removing all the covering which surround the beans and preparing the beans according to market requirements. Unintentional or intentional harvesting of cherries at several stages of maturation may have adverse impacts on coffee quality if these materials are processed together. Cherries at different stages of maturation should be separated and processed using different techniques in order to retain as much quality as possible. Cherries must undergo dry, semi-dry or wet processing as soon as possible after harvesting. The storage of fresh cherries in bags, heaps, hoppers or silos should not last more than eight hours. Otherwise unwanted fermentation will generate the dreaded "stinker" beans, which appear when the temperature before pulping exceeds $40-42^{\circ} \mathrm{C}$. Even if the temperature does not rise to the point of creating stinkers, uncontrolled fermentation may have other negative impacts on the cup. Coffee cherries should not be kept in plastic bags. The damp airtight atmosphere that develops inside plastic bags favors unwanted fermentation that damages coffee quality. Therefore, the main objective of this paper is to review on post-harvest and green bean coffee processing in Ethiopian.
\end{abstract}

Keywords: Green Coffee; Post Harvest; Processing

\section{Introduction}

Coffee (Coffea arabica L.), is a beverage drink in the world which is originate is the most popular side in Ethiopia; it is currently grown in many countries. Worldwide over 15 billion cups are consumed every day. In Ethiopia agricultural sector plays a central role in the economic and social life of the nation. Around 80 to $85 \%$ of people in Ethiopia are dependent on agriculture; among 80 to $85 \%$ about $40 \%$ of the sector contributes from cultivation of coffee $[7,8]$. in Ethiopia agricultural sector plays a central role in the economic and social life of the nation. Botanically, Coffee belongs to the family Rubiacea and the genus Coffea and the genus coffea consists of around 400 genera and 5000 spp. Among these economically important species are includes Coffee Arabica L. (Arabica coffee), Coffee cenophora L. (Robusta coffee), Coffee li- berica L. (Liberica coffee) and Coffee exelsa L. (Exelsa coffee). Those economically important species of coffee vary in natural heights, age of bearing, leaf size, pollination habit, chromosome number, caffeine content, berry size, etc that make one preferable than the other. The two main species of coffee cultivated on a world scale are Arabica coffee (Coffea arabica L.) and Robusta coffee (Coffea anaphora L.), which account for about $98-99 \%$ of the world total coffee production [12].

In fact, Ethiopia is the only center of origin and diversity of Arabica coffee. But, now a days, Arabica coffee is cultivated in most parts of the tropics, accounting for $80 \%$ of the world coffee market and about $70 \%$ of production. Economically, coffee is the second most exported commodity after oil, and employs over 100 million 
people worldwide [4-6]. The earlier use of coffee was as food, rather than as beverage. For instance, there are evidences which show that Oromo started using coffee as energy food long before its current popular use as beverage. There are also traditional beverages consumed locally, than the popular mode of consumption known worldwide. The traditional foods from coffee include coffee ball, Bunaqalaa and Qorii, while traditional drinks are Qutii, Hojjaa and Chamoo [3]. It is the $2^{\text {nd }}$ most valuable export commodity on the world after oil. Socially, Coffee is used in serving a respected guest; gathering neighbors to discuss on economic, social and other matters or celebrities. Coffee is also used for medicinal purposes; such as a good effect that is both temporary and transitory. It has stimulatory effect which results in increased capacity for both mental activity and muscular works [1]. More than 80 countries produce coffee in the world, and the total area of the production in Ethiopia is estimated to be about 450,000-600,000ha. Average annual coffee production is estimated to about 350,000 tons and productivity of about $0.71 \mathrm{t} / \mathrm{ha}$. Currently, Ethiopia export only 40 to $45 \%$ of the total coffee produced, 55-60\% of coffee beans are consumed locally. Thus, our country is 1st in Africa, 3rd in the world and Brazil is the leading country in exporting coffee to the world market. Many farmers, particularly in parts of kaffa and Ilulbabor were forced to cut or uproot the coffee plants in order to grow food crops because of low productivity, quality and market problems [2].

At the beginning of the $18^{\text {th }}$ century, visiting Arab traders also found the drink agreeable and, from then on, coffee was shipped to the Arabian peninsular. A demand for coffee quickly developed amongst the peoples of Arabia and coffee plantations were established in Yemen. Later, during the $18^{\text {th }}$ and $19^{\text {th }}$ centuries, there was a steady expansion of coffee drinking throughout the world and Arabica coffee was exported to many countries, with the source planting material originating from either Ethiopia or Yemen [11].

Berry (immature) and cherry (after ripening) attached to the branches by fruit stalk which it takes 8 to 12 months to develop fruit from flowering and 7-9 months from fruit setting to ripening. Only around $40 \%$ of flower develops into fruit as the rest shed because of nutrition and environmental factor at flowering. The immature fruit is green in color and ripened fruit is ovoid, glabrous in shape and red in color and has an average width of $10-15 \mathrm{~mm}$ and length of $16 \mathrm{~mm}$. Normally two seeds per fruit with flat side pressed together, but abnormal of pea berry, triage and elephant seeds exist. Coffee bean and berry has different structures. These includes: center cut, beans (endosperm), silver skin (seed testa), parchments, pectin layers, pulp and outer skin [1].
Unintentional or intentional harvesting of cherries at several stages of maturation may have adverse impacts on coffee quality if these materials are processed together. Cherries at different stages of maturation should be separated and processed using different techniques in order to retain as much quality as possible. Coffee processing aims to lower the water content of fresh cherries to a level which allows the preservation of beans (about 11-12\%), removing all the covering which surround the beans and preparing the beans according to market requirements. Therefore, the main objective of this paper is to review on Post-harvest and green coffee Processing under Ethiopian condition.

\section{Processing of harvested green bean coffee}

Harvested ripe coffee berries contain parchment hull and pulp, which are to be removed to get the coffee beans or the seeds. This can be done in two methods, i.e. dry or wet method. In dry method, the berries are dried and the covering over the dried seed is removed by hulling. By wet method, initially for removing the pulp, ripe coffee berries are passed through coffee pulping machine. De-pulped coffee berries contain mucilaginous coatings which are removed by different methods, i.e., microbial fermentation, pectin-digestion enzymes, different water washing treatments. The obtained beans after pulp and mucilaginous coating removal, contains another other hull, which are removed after drying of coffee beans. Coffee beans are generally dried under the sun, where drying may take 4-5 days depending on the weather condition [13].

Coffee cherries may undergo dry, semi-dry or wet processing as soon as possible after harvesting. The storage of fresh cherries in bags, heaps, hoppers or silos should not last more than 8 hours. Otherwise unwanted fermentation will generate the dreaded "stinker" beans, which appear when the temperature before pulping exceeds $40-42^{\circ} \mathrm{C}$. Even if the temperature does not rise to the point of creating stinkers, uncontrolled fermentation may have other negative impacts on the cup. In emergency situations fresh cherries may be stored for a longer period if they are kept under water. Coffee cherries should not be kept in plastic bags. The damp airtight atmosphere that develops inside plastic bags favors unwanted fermentation that damages coffee quality.

\section{Dry-Processing}

Most often dry processing is used after non-selective harvesting, i.e. after stripping or mechanical harvesting. In this case, when the coffee reaches the processing line it is a mixture of unripe, ripe, overripe and partially dry cherries along with leaves and sticks as well as earth and stones when coffee is harvested directly on the 
ground. The aim of dry processing is to clean the coffee cherries and to separate them, to the extent possible, according to their moisture content. Cherries at different moisture levels are then dried separately to obtain an evenly dried product. Unfortunately many growers who produce natural coffees simply ignore these steps and go directly from harvesting to drying without any cleaning or separation. The result is a product of lower quality. Natural coffees that have been properly dry-processed can be a quality product with their own market. Natural coffees are a basic ingredient of espresso blends and, as such, they enjoy a growing demand, especially for high-quality products.

Although the bulk of Robusta production is dry processed, washed Robustas have been offered by some countries like India, Democratic Republic of Congo and Indonesia for many years. Recent tendencies point to a slow shift to Robusta washing in several areas of the world. Some experts claim that washed Robustas may be a good substitute for low quality Arabicas, especially in espresso blends. Some Robusta growers, particularly in Uganda and Brazil, are shifting to the pulped natural system. Dry pulping should only be attempted in cases where there are almost $100 \%$ of ripe cherries.

\section{Wet processing}

In conventional devices coffee cherries are pulped in a water flow. As the water content of coffee cherries is high, most pulpers can operate with little or no water provided that alterations are made to ensure that the feeding of cherries and the removal of parchment and pulp can take place without water. Research along these lines has led to a substantial reduction of water consumption in the pulping operation.

Wet processing is to remove pulp and mucilage from ripe coffee cherries in an environmentally friendly way. In order to process only fresh ripe cherries, it is necessary to harvest only such cherries or to separate the undesirable products before pulp and mucilage are removed. The description of the wet process will be divided into cleaning and separation. Most producers of washed Arabica cog fees use selective harvesting. Wet processing after strip harvesting is only the case for Arabicas in Brazil, Hawaii and Australia as well as for Robustas in a few countries. Labor shortages and high harvesting costs are, however, forcing more countries to consider stripping as a means of lowering production costs. Even if harvesting is selective, the types of products harvested must be considered when deciding which cleaning steps and pulping systems to use. When the harvested product contains only a few impurities, for instance, it may not be necessary to sift it. Flotation may be bypassed if there are no over-ripe cherries.
Arabica cherries are easier to pulp than Robusta cherries. As a result the capacity of pulpers falls when processing Robusta coffees. Raoeng pulpers should not be used in new wet mills because of their high water and energy consumption. Disk pulpers have a tendency to lose the capacity and efficiency of separation of pulp from parchment rather quickly as the bulbs wear out. Frequent monitoring and maintenance are therefore critical for optimum performance. Stones and sticks can be very damaging to all pulping systems and even more so in the case of the copper sleeves of drums pulpers. If it cannot be guaranteed that the harvested cherries are free from foreign materials, pulping should be preceded by a flotation device to remove stones and other impurities. Steel sleeves are more resistant to wear and tear and damage than copper sleeves. The generation of pulp fiber is a problem for many pulping systems. Fiber is very difficult to separate from water and high cost special equipment is required. The pulping system that produces the least fiber is the slotted screen one. A pulping system that produces whole pulp rather than pulp pieces and fiber is environmentally superior.

Some researchers claim that soaking, i.e. keeping parchment coffee under clean water for a number of hours after it has been demucilaged lessens bitterness and favors quality. This could be an interesting option for quality conscious millers because the parchment could be soaked after the mechanical removal of mucilage. Although this procedure requires tanks and batch processing and causes weight losses, the water will not be contaminated and can easily be recycled. Weight losses will be lower than in fermentation provided that coffee is soaked for a shorter period than for the fermentation process. The weight gains due to mechanical mucilage removal may be lost if drying does not start shortly after demucilaging. The interval between mucilage removal and drying should not exceed 6 hours. Furthermore, the mechanical removal of mucilage allows the design of more compact mills and the construction of compact modules for wet processing.

\section{Drying}

During drying operation significant moisture reduction from $53 \%$ to about $12 \%$ was reported. Electric dryers can be used where temperature control is more precise and drying time can be reduced, but chances of over-drying or un-uniform temperature distribution inside dryer, may affect the final produced coffee quality. Dried coffee seeds are passed through the hulling machine to remove the hull and by mechanical aspiration the hulls are separated from the seeds. Hulled coffee seeds are manually inspected and defected/discolored seeds are removed from the whole lot. Electronic colour sorters may also be used to eliminate defective 
seeds, as alternate to manual sorting. Sorted good quality beans are graded based on seed size, colour, and other standard tests to estimate the brewing quality of the finished coffee. Out of wet and dry processing method, wet processing of coffee seeds results in better quality green coffee $[9,10]$.

Coffee is dried by increasing the temperature of the bean to evaporate water. In sun drying beans are heated by direct exposure to the sun and by radiation from a heated surface (in the case of drying grounds). Convection and wind move the saturated air away. In mechanical drying beans are heated by the passage of hot air which also carries the moisture away. Temperatures must be monitored during natural and artificial drying. Coffee temperatures should not exceed $40^{\circ} \mathrm{C}$ for parchment and $45^{\circ} \mathrm{C}$ for cherries. It is often thought that overheating can only occur in mechanical dryers. Maximum tolerated temperatures may well be exceeded in sun drying if the beans are not revolved frequently or, in the case of fine Arabica beans, protected by plastic sheets, a tarpaulin or a roof during the hottest hours of the day. Temperature control becomes more critical in the later stages of the drying process when moisture levels are low.

In the early stages, there is a lot of water to be removed and relatively high air temperatures are not likely to induce the beans to overheat. At this stage, air flow to remove the surface moisture is more important than the temperature itself. As coffee moisture decreases water must move from the center to the periphery of the beans at a speed that depends on the outer air temperature and on the intrinsic physical characteristics of the bean itself. Since there is no more free moisture near or at the surface, the beans heat quickly. At this point the difference between air and coffee temperatures are considerably reduced and the drying temperature must be carefully monitored to avoid damaging the beans. In sun drying, temperature is controlled by revolving the coffee frequently. Parchment should be covered before it becomes too hot. In machine drying, the temperature is controlled by fuel feeding, air flows, etc. Coffee moisture is high, $50-55 \%$ or even more, at the beginning of the drying period so high air temperatures may be used without risk of overheating the coffee.

In most types of dryers the coffee will not heat beyond $30^{\circ} \mathrm{C}$ while the moisture is high even though the air temperature may reach $90^{\circ} \mathrm{C}$. It is widely accepted that the color and quality of Robusta coffees benefit from a high air temperature at the initial stages of drying. Air temperature must be lowered as drying progresses. Control of the air temperature is critical towards the end of the drying process because the coffee starts to gain temperature rapidly.
The damage caused by overheating depends on coffee moisture content, the temperature and the time coffee is exposed to overheating. The damage to beans may take several forms: parchment cracking, bending, bleaching, undue widening of the center cut, toasted beans, etc., all of which lead to quality losses. Parchment cracking exposes the beans to attacks by microorganisms during storage. Bent beans indicate severe overheating that some claim causes sour flavors and a flat cup. Overheating at the early stages of drying without a sufficient air flow to remove moisture may cause the stewing of coffee that can give it a cooked flavor. Beans that are overheated may have their surface crystallized, so that moisture can no longer leave the interior of the bean. This impermeable surface will crack in storage and the bean will bleach as moisture gradually moves out. The speed of drying cannot be increased above the speed at which moisture migrates from the center to the periphery of the bean. The speed at which water migrates in response to the temperature gradient artificially created is limited. This is a physical characteristic of the coffee beans and it cannot be changed. Attempts to accelerate drying beyond accepted limits will always leave moisture in the center of the bean. This moisture will move out later, which will have a negative effect on the aspect and the quality of the coffee. Slow drying of coffee is a good solution to homogenize coffees received with uneven moisture contents.

As a rule, coffee that is dried more slowly will have a more homogeneous moisture content and a more uniform color because longer drying grants the beans more time to exchange moisture and to equalize their moisture content. In recent years some experts have associated metallic tastes in brewed coffee with unduly short drying times. Evenly dried coffees fetch better prices because they have a more uniform color, a better aspect and roast better. It is highly desirable to have coffees with uniform moisture content at the end of the drying process. The fact that the moisture meter indicates $12 \%$ has nothing to do with homogeneous drying because meters measure average moisture. There may be beans with moisture levels ranging from 9 to $15 \%$ although the average moisture may still read the desirable $12 \%$.

As a general, Coffee moisture remains at $12 \%$ when air moisture at storage is between 60 and $65 \%$. In humid areas it is usual to dry coffee to 10 or $11 \%$ to increase storage time before coffee picks up moisture from the air. In other areas drying stops at 13 or $14 \%$ to account for moisture losses in hulling. Moisture levels below 10 or $11 \%$ increase the breakage of beans at hulling, especially with Robustas that are more brittle. Moisture contents above $12 \%$ increase the risks of quality and weight loss in storage. 
Grading

Few countries export ungraded coffee today, and even those that do still remove oversized and very small beans in an operation that requires graders. Size grading generates improved operational efficiency and additional revenues. In some countries color defects are still sorted by hand, with workers sitting on the floor, at individual tables or on either side of long tables equipped with mobile belts. When sorting is done by hand, workers may also sort defects other than off-color beans. There is no technical reason to color sort by hand instead of using machines. Hand sorting is still performed in a few countries in order to maintain employment or because labor is still inexpensive.

\section{Liquoring and storing}

After dehulling the coffee beans, the dehulled beans are roasted during which the distinctive coffee aroma originates due to a number of physico-chemical changes. Coffee roasters can be batch or continuous type and with development of technologies, now roasters are available which has temperature controls along with humidity, roaster gas recirculation facilities, precise roasting time control etc. Roaster temperature is maintained around $260^{\circ} \mathrm{C}$ and the temperature of the coffee beans may rise to $200^{\circ} \mathrm{C}$. During the roasting operation, the coffee beans losses all the moisture and some other volatiles. There is change in volume and colour during the roasting operation. Colour of the bean changes from dullgreen to brown colour and the bean texture also becomes brittle after roasting. Roasted coffee beans are cooled and grinded. Size of grounded coffee beans depends on its end use, where the particle size and particle size distribution of coffee powder impacts the turbidity, brewing time and other properties. Coffee powder after grinding is recommended to kept under air-tight, vacuum or in presence of inert gases, since the presence of oxygen affects the quality to a much extent. Open packaging of coffee powder results in losses of volatiles in atmosphere. Coffee are brewed in hot water under different conditions like coffee to hot water ratio, particle characteristics of the coffee powder, hot water temperature, type of mixing, brewing time etc. All this factors affects the brewed coffee getting extracted which can be measure with standard hydrometer, calibrated by authorized coffee agencies $[9,10]$.

\section{Conclusions}

Botanically, Coffee belongs to the family Rubiacea and the genus Coffea. In Ethiopia agricultural sector coffee plays a central role for the economic and social life of the nation. Around 80 to $85 \%$ of people in Ethiopia are dependent on agriculture; among 80 to $85 \%$ about $40 \%$ of the sector contributes from cultivation of coffee. Coffee is a favorite beverage for many people that consumed for its stimulating effect which is caused by the presence of caffeine whose many of us are not much aware of how the coffee is cultivated, processed and the science behind the characteristic coffee flavour development from the coffee seeds. This paper in brief reviewed about the processing aspect of coffee from harvest of berries to the green coffee processing. The characteristic coffee aroma and flavour was reported to be the combined effects of during the processing of coffee beans. It is understood that processing is a very important aspect for good quality coffee beans. After processing, proper care needs to be taken for package and storage of hygroscopic coffee bean.

\section{Conflict of Interest}

Regarding the publication of this manuscript, there is no any conflict of interest.

\section{Acknowledgement}

We would heartedly like to thank and praise the Lord Almighty God in giving us strength and wellbeing to successfully complete the study. We also want to thanks for all Ambo University horticulture department staff for all their help and moral support. Finally, all the reference materials used in this paper are dully acknowledged.

\section{Bibliography}

1. Alemayehu T., et al. "Coffee Development and Marketing Improvement plan in Ethiopia”. In: Girma Adugna, Bayetta Belachew, Tesfaye Shimber, EndaleTaye, TayeKufa (eds). Coffee diversity and knowledge Proceedings of National Workshop Four Decades of Coffee Research and Development in Ethiopia". Addis AEthiopia (2008): 375-381.

2. Arega Zeru. "Diversity of Arabica coffee population in Afromontane rain forest of Etiopia in relation to Colletotrichumkahawae and Gibberellaxylaroidus". Msc Thesis. Addis Ababa University, Etiopia. (2006).

3. Gole TW., et al. "Coffee is Ethiopia's gift to the world. In Coffee-a global success (H.W. Lack, K. Grotz and Tadesse W. Gole, eds.). Botanischer Garten and Botaniches Museum BerlinDahlem, Berlin (2013): 12-19.

4. Gray Q., et al. Ethiopia: Coffee Annual Report. GAIN Report No.ET 1302. Jirata and Assafa, (2000). The status of coffee berry disease in Oromiya. in processing of the workshop on control coffee berry disease in Ethiopia 13-15 August 1999. Addis Ababa, Ethiopia118 (2013). 
5. Pendergrast M. "Uncommon grounds: The history of coffee and how it transformed our world, Basic Books, New York (2010): 424.

6. Petit N. "Ethiopia's Coffee Sector: A Bitter or Better Future?". Journal of Agrarian Change 7.2 (2007): 225-263.

7. Ponte S. “The 'Latte Revolution'?Regulation, Markets and Consumption in the Global Coffee Chain". World Development 30.7 (2002): 1099-1122.

8. SN Ghaiwat and P Arora. "Detection and Classification of Coffee diseases Using Image processing Techniques". A Review 2.3 (2014).

9. Manay NS and Shadaksharaswamy M. "Foods: Facts and Principles". New Age International (P) Limited, Publishers, New Delhi, India, 12 (1987): 131-135.2.

10. Potter NN and Hotchkiss JH. "Beverages". Food Science Springer Science and Business Media. 19 (1998): 451-457.

11. Anonymous A. "Coffee growing information for the beginners". AgriFarming: \#1 source of farming in India (2019).

12. Muluneh Bekele. 2018. "Review on Management of coffee berry disease in Ethiopia". Journal of food science and quality management 76 (2018): 73-76.

13. Soumitra Banerjee., et al. "Coffee Cultivation, Processing and Aroma: A Detailed Review". Acta Scientific Nutritional Health 3.4 (2019): 14-18.

\section{Volume 3 Issue 7 July 2019}

(C) All rights are reserved by Bikila Ollika Fufa., et al. 